\title{
Risk adjustment models for interhospital comparison of CS rates using Robson's ten group classification system and other socio-demographic and clinical variables
}

\author{
Paola Colais ${ }^{1 *}$, Maria P Fantini ${ }^{2}$, Danilo Fusco ${ }^{1}$, Elisa Carretta ${ }^{2}$, Elisa Stivanello ${ }^{2}$, Jacopo Lenzi ${ }^{2}$, Giulia Pieri ${ }^{2}$ \\ and Carlo A Perucci ${ }^{3}$
}

\begin{abstract}
Background: Caesarean section (CS) rate is a quality of health care indicator frequently used at national and international level. The aim of this study was to assess whether adjustment for Robson's Ten Group Classification System (TGCS), and clinical and socio-demographic variables of the mother and the fetus is necessary for interhospital comparisons of CS rates.

Methods: The study population includes 64,423 deliveries in Emilia-Romagna between January 1, 2003 and December 31, 2004, classified according to theTGCS. Poisson regression was used to estimate crude and adjusted hospital relative risks of CS compared to a reference category. Analyses were carried out in the overall population and separately according to the Robson groups (groups I, II, III, IV and V-X combined). Adjusted relative risks (RR) of CS were estimated using two risk-adjustment models; the first (M1) including the TGCS group as the only adjustment factor; the second (M2) including in addition demographic and clinical confounders identified using a stepwise selection procedure. Percentage variations between crude and adjusted RRs by hospital were calculated to evaluate the confounding effect of covariates.
\end{abstract}

Results: The percentage variations from crude to adjusted RR proved to be similar in M1 and M2 model. However, stratified analyses by Robson's classification groups showed that residual confounding for clinical and demographic variables was present in groups I (nulliparous, single, cephalic, $\geq 37$ weeks, spontaneous labour) and III (multiparous, excluding previous CS, single, cephalic, $\geq 37$ weeks, spontaneous labour) and IV (multiparous, excluding previous CS, single, cephalic, $\geq 37$ weeks, induced or CS before labour) and to a minor extent in groups II (nulliparous, single, cephalic, $\geq 37$ weeks, induced or CS before labour) and IV (multiparous, excluding previous CS, single, cephalic, $\geq 37$ weeks, induced or CS before labour).

Conclusions: The TGCS classification is useful for inter-hospital comparison of CS section rates, but residual confounding is present in the TGCS strata.

\section{Background}

Caesarean section (CS) rate is one of the most frequently used indicators of health care quality at the national and international level for clinical governance and outcome research. Hospitals and health-care systems are often compared on the basis of this indicator with the implicit

\footnotetext{
* Correspondence: colais@asplazio.it

'Department of Epidemiology, Regional Health Service, Lazio Region, Italy Full list of author information is available at the end of the article
}

assumption that lower rates reflect more appropriate practice, although the rate that defines optimum quality of care is undefined and seems to depend on the characteristics of the populations under study [1]. The World Health Organization has indicated that a CS rate greater than 10$15 \%$ is not justified in any region of the world. Rates are higher in developed countries, Latin America and the Caribbean, and lower in other developing countries [2-6].

In 2005, the Italian CS rate was the highest in Europe (38.5\% vs. an average European rate of $23.7 \%$ ) and one 
of the highest in the world [6]. In Italy, national CS rates have increased from $32 \%$ in 2001 to $38.5 \%$ in 2005 . This increase was found both for primary CS and repeated CS. Primary caesarean deliveries contribute $2 / 3$ to the overall CS rate, although the contribution of repeated $\mathrm{CS}$ is higher in regions with high overall CS rates [7]. Primary caesarean deliveries are an important target for reduction, because they lead to an increased risk for repeated caesarean delivery [8-10]. Therefore, some authors suggested to focus on primary CS for interhospital comparison and quality improvement [11], and others, based on evidence suggesting that non-vertex and multiple births may have better outcomes with cesarean deliveries [12], omitted these categories from the calculation of CS rates and focused on nulliparous term cephalic singleton (NTCS) deliveries.

In 2001, a new classification for CS known as the "ten group" (TGCS) or Robson classification was proposed. This classification system categorizes women into $10 \mathrm{mu}$ tually exclusive groups, considering the following a priori criteria: parity, the previous obstetric record of the woman, the course of labour, including pre-labour CS, and gestational age [11]. Several studies used the Robson classification system to compare CS rates within specific subsets of an obstetric population to overcome many of the historic controversies that have arisen when comparing overall caesarean rates among different populations [13-17]. A recent systematic review [18] supported the use of TGCS classification over other classifications based on characteristics of parturients for auditing purposes and comparison of CS rates across different settings.

The TGCS classifies CS according to the characteristics of each woman and her pregnancy. However, caesarean delivery has many other indications such as fetal distress, dystocia, placenta previa, HIV, and other conditions of the mother and foetus [19]. The failure to account for such patient-specific risk factors may lead to biased interhospital comparisons [20,21]. The possible confounding effect is caused by the heterogeneous distribution of CS risk factors across hospitals, that is not taken into account in the a priori Robson classification.

A recent study addressing interhospital comparison of CS rates in women with a primary CS and those with NTCS deliveries emphasized a differential need to adjust for clinical variables of the mother and the foetus and for socio-demographic characteristics of the mother [22]. Adjustment proved to be warranted when the indicator of interest was primary CS rate but not when the indicator was NTCS CS rate. The aim of the present study is to define a risk-adjustment model for interhospital comparison using TGCS classification and clinical and socio-demographic characteristics of the mother and the fetus not included in the TGCS classification that are indications for CS.

\section{Methods}

\section{Study population}

Deliveries in Emilia-Romagna Region (Italy) from January 1, 2003 through December 31, 2004 were extracted from Hospital Discharge Abstracts of mothers and their babies (SDO), and Birth Certificates (CedaP). Record linkage was performed between the SDO and CedaP databases.

The SDO data includes demographics (ID number, sex, date and place of birth, place of residence), discharge ID, admission and discharge dates, discharge diagnoses and procedures (International Classification of Diseases, $9^{\text {th }}$ Revision, Clinical Modification ICD-IX-CM), ward(s) of hospitalization, date(s) of in-hospital transfer, and the regional code of the admitting facility.

Birth Certificates include demographic data of the mother, information on presentation and multiple pregnancy (singleton cephalic, singleton breech, trasverse or oblique lie, etc.), parity (nulliparous, multiparous), the course of labour and delivery (spontaneous labour, induced labour or CS before labour) and gestational age (defined as the number of completed weeks at the time of birth).

To identify the delivery by Hospital Discharge Abstracts of mothers and their babies (SDO), we used three different sources of information: DRGs 370-375, procedure codes ICD-9-CM 72.*-74.* and diagnosis codes ICD-9-CM 640.*676.*, V27.

DRG 370, procedure codes ICD-9-CM 74.0, 74.1, 74.2, 74.4, 74, 99 and diagnosis codes ICD-9-CM 669.7 were used to identify caesarean deliveries.

Mothers under the age of 11 or over the age of 50 years; mothers who were discharged from a hospital without an operating room; and infants with a birth weight under $550 \mathrm{~g}$ or over $6000 \mathrm{~g}$ were excluded.

CS rates were calculated as the ratio of caesarean deliveries to total deliveries.

Deliveries were retrospectively classified according to Robson's Ten Group Classification System (TGCS) using information in the databases

The following socio-demographic variables were considered as potential risk factors for caesarean sections: maternal age (classified as $<20,20-34$, or $\geq 35$ years), citizenship (Italian, from developing countries, from developed countries other than Italy) and educational level ( $\leq 5,6-8,9-13$, or $\geq 14$ years). Maternal and neonatal clinical factors that constitute indication for CS were extracted using primary and secondary discharge diagnoses of Hospital Discharge Abstracts (see Additional file 1: Appendix A for the ICD-9-CM codes).

The study was carried out in compliance with the Italian law on privacy (Art. 20-21, DL 196/2003) and the regulations of the Regional Health Authority of Emilia-Romagna on data management. Access to the data was approved by the hospital trust administration. 


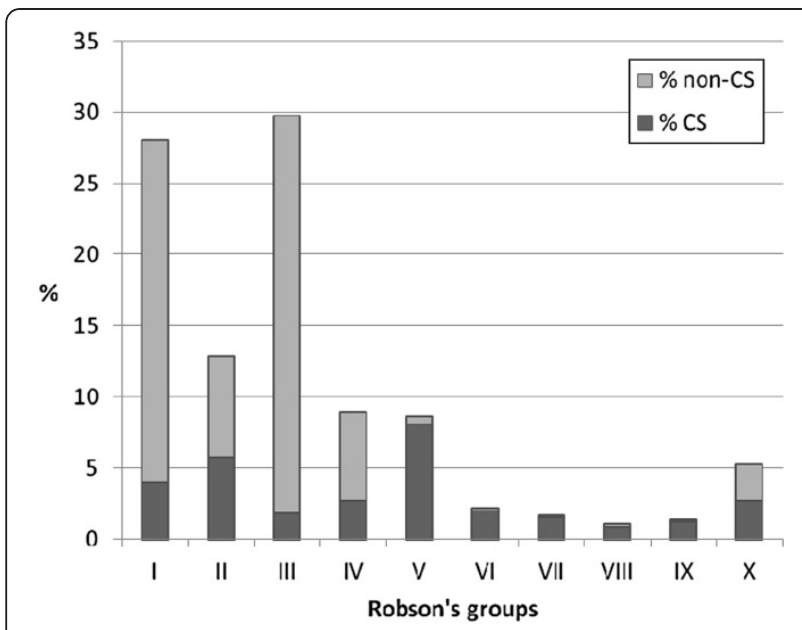

Figure 1 Percentage distribution of deliveries by TGCS over the total number of deliveries. Light gray: non-CS; gray: CS.
Data were anonymized at the regional statistical office where a unique identifier, the same for all databases, was assigned to each patient. This identifier does not allow to trace the patient's identity and other sensitive data. When anonymized administrative data are used to inform health care planning activities, the study is exempt from notification to the Ethics Committee and no specific written consent is needed to use patient information stored in the hospital databases.

\section{Statistical analysis}

Analyses were initially carried out on the entire population. We then analyzed the I-IV Robson groups separately, and the V-X Robson groups taken together. The last six Robson groups accounted for about $20 \%$ of all deliveries and could not be analyzed separately because of the small

Table 1 Crude and adjusted c-section RRs of hospitals

\begin{tabular}{|c|c|c|c|c|c|c|c|c|c|}
\hline Hospital & $\mathrm{n}$ & Crude RR & $\mathrm{p}$-value & Adj* RR & p-value & $\%$ variation $\dagger$ & Adj! RR & $\mathrm{p}$-value & $\%$ variation† \\
\hline A & 2,377 & 1.39 & $<0.001$ & 1.19 & $<0.001$ & -14.4 & 1.18 & $<0.001$ & -15.1 \\
\hline B & 1,306 & 1.36 & $<0.001$ & 1.25 & $<0.001$ & -8.1 & 1.26 & $<0.001$ & -7.4 \\
\hline C & 935 & 1.05 & 0.428 & 1.00 & 0.908 & -4.8 & 1.01 & 0.877 & -3.8 \\
\hline D & 344 & 1.27 & 0.006 & 1.35 & $<0.001$ & 6.3 & 1.37 & $<0.001$ & 7.9 \\
\hline E & 1,468 & 1.34 & $<0.001$ & 1.12 & 0.001 & -16.4 & 1.14 & $<0.001$ & -14.9 \\
\hline $\mathrm{F}$ & 1,677 & 1.41 & $<0.001$ & 1.12 & 0.001 & -20.6 & 1.09 & 0.006 & -22.7 \\
\hline G & 1,615 & 1.22 & $<0.001$ & 1.08 & 0.026 & -11.5 & 1.11 & 0.003 & -9.0 \\
\hline H & 459 & 1.71 & $<0.001$ & 1.34 & $<0.001$ & -21.6 & 1.31 & $<0.001$ & -23.4 \\
\hline I & 1,430 & 1.51 & $<0.001$ & 1.26 & $<0.001$ & -16.6 & 1.21 & $<0.001$ & -19.9 \\
\hline J & 2,096 & 1.39 & $<0.001$ & 1.18 & $<0.001$ & -15.1 & 1.17 & $<0.001$ & -15.8 \\
\hline K & 1,854 & 1.28 & $<0.001$ & 1.25 & $<0.001$ & -2.3 & 1.24 & $<0.001$ & -3.1 \\
\hline L & 4,389 & 1.02 & 0.550 & 0.90 & $<0.001$ & -11.8 & 0.90 & $<0.001$ & -11.8 \\
\hline M & 603 & 1.82 & $<0.001$ & 1.77 & $<0.001$ & -2.7 & 1.62 & $<0.001$ & -11.0 \\
\hline N & 547 & 1.38 & $<0.001$ & 1.13 & 0.044 & -18.1 & 1.13 & 0.038 & -18.1 \\
\hline O & 1,923 & 1.02 & 0.616 & 1.09 & 0.019 & 6.9 & 1.05 & 0.188 & 2.9 \\
\hline P & 2,120 & 1.38 & $<0.001$ & 1.28 & $<0.001$ & -7.2 & 1.28 & $<0.001$ & -7.2 \\
\hline Q & 4,377 & 1.14 & $<0.001$ & 1.02 & 0.431 & -10.5 & 1.03 & 0.261 & -9.6 \\
\hline R & 4,488 & 1.45 & $<0.001$ & 1.29 & $<0.001$ & -11.0 & 1.29 & $<0.001$ & -11.0 \\
\hline$S$ & 598 & 2.73 & $<0.001$ & 1.75 & $<0.001$ & -35.9 & 1.68 & $<0.001$ & -38.5 \\
\hline $\mathrm{T}$ & 304 & 2.45 & $<0.001$ & 1.76 & $<0.001$ & -28.2 & 1.72 & $<0.001$ & -29.8 \\
\hline U & 4,591 & 1.58 & $<0.001$ & 1.32 & $<0.001$ & -16.5 & 1.26 & $<0.001$ & -20.3 \\
\hline V & 4,430 & 1.26 & $<0.001$ & 1.06 & 0.009 & -15.9 & 1.03 & 0.159 & -18.3 \\
\hline W & 5,635 & 1.34 & $<0.001$ & 1.13 & $<0.001$ & -15.7 & 1.11 & $<0.001$ & -17.2 \\
\hline X & 6,374 & 1.44 & $<0.001$ & 1.35 & $<0.001$ & -6.2 & 1.31 & $<0.001$ & -9.0 \\
\hline Y & 1,770 & 1.33 & $<0.001$ & 1.25 & $<0.001$ & -6.0 & 1.23 & $<0.001$ & -7.5 \\
\hline
\end{tabular}

${ }^{*}$ Adjusted for Robson class.

† The $\%$ variation is computed as (crude RR-adj RR)*100/crude RR.

+. Adjusted for: age, citizenship, severe co-morbid illness of the mother, HIV, diabetes, hypertension, lung diseases, ante-partum haemorrhage/abruption placentae/ placenta praevia, eclampsia/pre-eclampsia, foetal-pelvic disproportion/excessive development of the infant, foetal anomalies, $\mathrm{RH}$-isoimmunisation, polyhydramnios, oligohydramnios, premature rupture of the membranes, problem of the amnios, congenital malformation, intrauterine growth retardation, post-maturity and macrosomia, Robson group. 
Table 2 Crude and adjusted c-section RRs of hospitals in group I

\begin{tabular}{|c|c|c|c|c|c|c|}
\hline Hospital & $n$ & Crude RR & p-value & Adj* RR & $\mathrm{p}$-value & $\%$ variationt \\
\hline A & 707 & 0.94 & 0.638 & 1.08 & 0.555 & 14.9 \\
\hline B & 397 & 0.99 & 0.953 & 1.12 & 0.467 & 13.1 \\
\hline C & 268 & 0.42 & 0.003 & 0.47 & 0.008 & 11.9 \\
\hline D & 107 & 0.70 & 0.303 & 0.74 & 0.386 & 5.7 \\
\hline $\mathrm{E}$ & 448 & 1.48 & 0.002 & 1.53 & $<0.001$ & 3.4 \\
\hline$F$ & 416 & 1.80 & $<0.001$ & 1.77 & $<0.001$ & -1.7 \\
\hline G & 508 & 0.92 & 0.586 & 1.02 & 0.887 & 10.9 \\
\hline $\mathrm{H}$ & 112 & 1.17 & 0.543 & 1.26 & 0.333 & 7.7 \\
\hline 1 & 305 & 1.60 & 0.001 & 1.73 & $<0.001$ & 8.1 \\
\hline J & 488 & 1.21 & 0.161 & 1.32 & 0.037 & 9.1 \\
\hline K & 572 & 1.38 & 0.008 & 1.49 & 0.001 & 8.0 \\
\hline L & 1,151 & 0.73 & 0.01 & 0.76 & 0.017 & 4.1 \\
\hline M & 243 & 3.85 & $<0.001$ & 2.43 & $<0.001$ & -36.9 \\
\hline N & 143 & 2.55 & $<0.001$ & 1.96 & $<0.001$ & -23.1 \\
\hline O & 582 & 1.35 & 0.013 & 1.31 & 0.016 & -3.0 \\
\hline$P$ & 616 & 1.44 & 0.001 & 1.51 & $<0.001$ & 4.9 \\
\hline Q & 1,177 & 0.30 & $<0.001$ & 0.34 & $<0.001$ & 13.3 \\
\hline R & 1,239 & 1.12 & 0.272 & 1.22 & 0.043 & 8.9 \\
\hline S & 99 & 3.31 & $<0.001$ & 2.62 & $<0.001$ & -20.8 \\
\hline $\mathrm{T}$ & 69 & 3.66 & $<0.001$ & 2.57 & $<0.001$ & -29.8 \\
\hline U & 1,382 & 1.95 & $<0.001$ & 1.84 & $<0.001$ & -5.6 \\
\hline V & 1,333 & 0.80 & 0.047 & 0.83 & 0.095 & 3.7 \\
\hline W & 1,284 & 1.19 & 0.081 & 1.30 & 0.007 & 9.2 \\
\hline$x$ & 1,965 & 2.47 & $<0.001$ & 2.21 & $<0.001$ & -10.5 \\
\hline Y & 564 & 1.33 & 0.021 & 1.28 & 0.036 & -3.8 \\
\hline
\end{tabular}

* Adjusted for: age, citizenship, severe co-morbid illness of the mother, HIV, diabetes, hypertension, ante-partum haemorrhage/abruption placentae/ placenta praevia, eclampsia/pre-eclampsia, foetal-pelvic disproportion/ excessive development of the infant, foetal anomalies, RH-isoimmunisation, polyhydramnios, oligohydramnios, abortion threats/assisted fecundation, congenital malformation, intrauterine growth retardation, post-maturity and macrosomia.

† The $\%$ variation is computed as (crude RR-adj RR)*100/crude RR.

number of deliveries in these groups by hospital. Crude and adjusted relative risks of CS for each hospital were calculated using as the reference category hospitals with the lowest CS rates. These hospitals were identified by means of a recursive procedure developed by P.Re.Val.E. Project [23]. Adjusted RR of CS (caesarean section risk for patients admitted to a specific hospital vs. caesarean section risk for patients admitted to the reference category) were obtained by using modified Poisson regression models based on the Huber sandwich estimate, that improves efficiency in mean-variance relationship.

Specifically, two risk adjustment models were set up. The first model (M1) was built using TGCS as the only potential confounding factor. The second model (M2) included, in addition to TGCS, a number of potential
Table 3 Crude and adjusted c-section RRs of hospitals in group II

\begin{tabular}{|c|c|c|c|c|c|c|}
\hline Hospital & $\mathbf{n}$ & Crude RR & p-value & Adj* RR & p-value & $\%$ variationt \\
\hline A & 269 & 1.61 & $<0.001$ & 1.52 & $<0.001$ & -5.6 \\
\hline B & 145 & 1.54 & $<0.001$ & 1.51 & $<0.001$ & -1.9 \\
\hline C & 99 & 1.04 & 0.756 & 0.99 & 0.952 & -4.8 \\
\hline D & 37 & 2.13 & $<0.001$ & 2.15 & $<0.001$ & 0.9 \\
\hline$E$ & 260 & 1.11 & 0.257 & 1.13 & 0.159 & 1.8 \\
\hline $\mathrm{F}$ & 347 & 1.24 & 0.006 & 1.25 & 0.004 & 0.8 \\
\hline G & 324 & 1.18 & 0.040 & 1.22 & 0.012 & 3.4 \\
\hline $\mathrm{H}$ & 81 & 1.78 & $<0.001$ & 1.63 & $<0.001$ & -8.4 \\
\hline | & 202 & 1.36 & $<0.001$ & 1.35 & $<0.001$ & -0.7 \\
\hline J & 315 & 1.09 & 0.330 & 1.09 & 0.297 & 0.0 \\
\hline K & 226 & 1.53 & $<0.001$ & 1.46 & $<0.001$ & -4.6 \\
\hline $\mathrm{L}$ & 504 & 0.99 & 0.871 & 0.98 & 0.787 & -1.0 \\
\hline M & 54 & 0.65 & 0.087 & 0.64 & 0.070 & -1.5 \\
\hline N & 118 & 0.78 & 0.112 & 0.79 & 0.130 & 1.3 \\
\hline O & 143 & 0.86 & 0.244 & 0.85 & 0.228 & -1.2 \\
\hline P & 369 & 1.41 & $<0.001$ & 1.39 & $<0.001$ & -1.4 \\
\hline Q & 644 & 1.22 & 0.003 & 1.20 & 0.007 & -1.6 \\
\hline R & 630 & 1.34 & $<0.001$ & 1.33 & $<0.001$ & -0.7 \\
\hline S & 113 & 2.26 & $<0.001$ & 2.14 & $<0.001$ & -5.3 \\
\hline $\mathrm{T}$ & 36 & 2.11 & $<0.001$ & 2.05 & $<0.001$ & -2.8 \\
\hline U & 405 & 1.62 & $<0.001$ & 1.54 & $<0.001$ & -4.9 \\
\hline V & 674 & 1.08 & 0.267 & 1.05 & 0.482 & -2.8 \\
\hline W & 779 & 1.22 & 0.002 & 1.21 & 0.002 & -0.8 \\
\hline X & 649 & 0.72 & $<0.001$ & 0.75 & $<0.001$ & 4.2 \\
\hline Y & 266 & 1.51 & $<0.001$ & 1.47 & $<0.001$ & -2.6 \\
\hline
\end{tabular}

* Adjusted for: age, severe co-morbid illness of the mother, diabetes, antepartum haemorrhage/abruption placentae/placenta praevia, eclampsia/preeclampsia, foetal-pelvic disproportion/excessive development of the infant, premature rupture of the membranes, post-maturity and macrosomia. † The $\%$ variation is computed as (crude RR-adj RR)*100/crude RR.

confounders (demographic and clinical variables related to the mother and foetus) selected according to available scientific evidence. These include age, citizenship, severe co-morbid illness of the mother, diabetes, hypertension, HIV, lung diseases, ante-partum haemorrhage/abruption placentae/placenta praevia, eclampsia/pre-eclampsia, foetal-pelvic disproportion/excessive development of the infant, polyhydramnios, oligohydramnios, isoimmunisation, premature rupture of the membranes, abortion threats/assisted fecundation, congenital malformation, problem of the amnios, post-maturity and macrosomia, intrauterine growth retardation (see Additional file 1 for the ICD-9-CM codes). A stepwise selection procedure (significance level for entry of 0.10 and 0.05 for stay), was used to remove variables unrelated to CS. 
Table 4 Crude and adjusted c-section RRs of hospitals in group III

\begin{tabular}{|c|c|c|c|c|c|c|}
\hline Hospital & $n$ & Crude RR & p-value & Adj* RR & $p$-value & $\%$ variationt \\
\hline A & 684 & 0.94 & 0.770 & 1.04 & 0.855 & 10.6 \\
\hline B & 408 & 1.13 & 0.614 & 1.27 & 0.295 & 12.4 \\
\hline C & 327 & 0.35 & 0.021 & 0.38 & 0.034 & 8.6 \\
\hline D & 120 & 1.15 & 0.733 & 1.18 & 0.669 & 2.6 \\
\hline$E$ & 347 & 0.86 & 0.604 & 0.92 & 0.755 & 7.0 \\
\hline$F$ & 379 & 0.24 & 0.005 & 0.21 & 0.002 & -12.5 \\
\hline G & 393 & 0.76 & 0.342 & 0.89 & 0.671 & 17.1 \\
\hline $\mathrm{H}$ & 120 & 0.96 & 0.924 & 1.14 & 0.771 & 18.8 \\
\hline | & 460 & 0.90 & 0.671 & 1.00 & 0.999 & 11.1 \\
\hline J & 616 & 1.60 & 0.007 & 1.68 & 0.001 & 5.0 \\
\hline K & 586 & 1.57 & 0.012 & 1.70 & 0.002 & 8.3 \\
\hline $\mathrm{L}$ & 1,295 & 0.73 & 0.077 & 0.77 & 0.127 & 5.5 \\
\hline M & 150 & 5.82 & $<0.001$ & 3.69 & $<0.001$ & -36.6 \\
\hline N & 106 & 5.21 & $<0.001$ & 5.04 & $<0.001$ & -3.3 \\
\hline O & 717 & 1.70 & 0.001 & 1.72 & $<0.001$ & 1.2 \\
\hline$P$ & 576 & 1.72 & 0.002 & 1.76 & 0.001 & 2.3 \\
\hline Q & 1,325 & 0.31 & $<0.001$ & 0.35 & $<0.001$ & 12.9 \\
\hline R & 1,282 & 1.42 & 0.015 & 1.45 & 0.009 & 2.1 \\
\hline$S$ & 103 & 2.68 & 0.001 & 2.96 & $<0.001$ & 10.4 \\
\hline $\mathrm{T}$ & 77 & 5.08 & $<0.001$ & 3.50 & $<0.001$ & -31.1 \\
\hline U & 1,283 & 2.54 & $<0.001$ & 2.21 & $<0.001$ & -13.0 \\
\hline V & 1,182 & 0.58 & 0.008 & 0.54 & 0.003 & -6.9 \\
\hline W & 1,664 & 1.20 & 0.189 & 1.25 & 0.101 & 4.2 \\
\hline$x$ & 1,926 & 3.40 & $<0.001$ & 2.93 & $<0.001$ & -13.8 \\
\hline Y & 491 & 1.17 & 0.466 & 1.12 & 0.579 & -4.3 \\
\hline
\end{tabular}

* Adjusted for: age, severe co-morbid illness of the mother, HIV, diabetes, hypertension, lung diseases, ante-partum haemorrhage/abruption placentae/ placenta praevia, eclampsia/pre-eclampsia, foetal-pelvic disproportion/ excessive development of the infant, foetal anomalies, RH-isoimmunisation polyhydramnios, oligohydramnios, problem of the amnios, congenital malformation, intrauterine growth retardation, post-maturity and macrosomia. t The $\%$ variation is computed as (crude RR-adj RR)*100/crude RR.

Stratum-specific models were defined for groups I to IV and V-X that included only clinical and demographic variables selected using a stepwise selection procedure.

Adjusted relative risks (RRs) and percentage variations between crude and adjusted RRs by hospital were then calculated to evaluate the amount of confounding. The presence of confounding was defined as a percentage variation $\geq 10 \%$ between crude and adjusted RRs [24,25]. The same hospitals selected as reference group in the overall population were used as the reference group in the stratified analyses. The significance level for the RR was set at 5\% $(\mathrm{p}<0.05)$. All analyses were performed using SAS Version 8.02.
Table 5 Crude and adjusted c-section RRs of hospitals in group IV

\begin{tabular}{|c|c|c|c|c|c|c|}
\hline Hospital & $\mathbf{n}$ & Crude RR & p-value & Adj* RR & p-value & $\%$ variationt \\
\hline A & 188 & 1.42 & 0.004 & 1.23 & 0.070 & -13.4 \\
\hline B & 105 & 1.80 & $<0.001$ & 1.58 & $<0.001$ & -12.2 \\
\hline C & 73 & 1.51 & 0.013 & 1.47 & 0.017 & -2.6 \\
\hline D & 35 & 2.36 & $<0.001$ & 2.50 & $<0.001$ & 5.9 \\
\hline$E$ & 127 & 1.08 & 0.621 & 1.07 & 0.637 & -0.9 \\
\hline$F$ & 187 & 0.82 & 0.213 & 0.85 & 0.289 & 3.7 \\
\hline G & 120 & 1.02 & 0.930 & 1.04 & 0.819 & 2.0 \\
\hline $\mathrm{H}$ & 44 & 1.70 & 0.005 & 1.52 & 0.020 & -10.6 \\
\hline | & 168 & 1.47 & 0.002 & 1.41 & 0.004 & -4.1 \\
\hline J & 242 & 1.30 & 0.025 & 1.16 & 0.178 & -10.8 \\
\hline K & 162 & 1.50 & 0.001 & 1.41 & 0.003 & -6.0 \\
\hline L & 316 & 0.95 & 0.647 & 0.92 & 0.487 & -3.2 \\
\hline M & 43 & 0.64 & 0.206 & 0.62 & 0.157 & -3.1 \\
\hline N & 91 & 0.26 & 0.001 & 0.27 & 0.001 & 3.8 \\
\hline O & 143 & 0.58 & 0.010 & 0.57 & 0.009 & -1.7 \\
\hline$P$ & 225 & 1.22 & 0.102 & 1.13 & 0.287 & -7.4 \\
\hline Q & 398 & 1.28 & 0.015 & 1.20 & 0.059 & -6.3 \\
\hline $\mathrm{R}$ & 410 & 1.76 & $<0.001$ & 1.69 & $<0.001$ & -4.0 \\
\hline S & 71 & 2.49 & $<0.001$ & 2.30 & $<0.001$ & -7.6 \\
\hline $\mathrm{T}$ & 40 & 2.26 & $<0.001$ & 1.91 & $<0.001$ & -15.5 \\
\hline U & 370 & 1.77 & $<0.001$ & 1.56 & $<0.001$ & -11.9 \\
\hline V & 266 & 0.96 & 0.755 & 0.87 & 0.250 & -9.4 \\
\hline W & 671 & 1.17 & 0.102 & 1.18 & 0.074 & 0.9 \\
\hline X & 527 & 0.47 & $<0.001$ & 0.48 & $<0.001$ & 2.1 \\
\hline Y & 151 & 1.17 & 0.274 & 1.04 & 0.777 & -11.1 \\
\hline
\end{tabular}

* Adjusted for: age, severe co-morbid illness of the mother, lung diseases, ante-partum haemorrhage/abruption placentae/placenta praevia, eclampsia/ pre-eclampsia, foetal-pelvic disproportion/excessive development of the infant, oligohydramnios, premature rupture of the membranes, abortion threats/ assisted fecundation, congenital malformation, post-maturity and macrosomia. † The \% variation is computed as (crude RR-adj RR)*100/crude RR.

\section{Results}

A total of 64,423 deliveries in Emilia-Romagna occurred between January 1, 2003, and December 31, 2004. The overall crude CS rate was $30.4 \%$, and the CS rate in the reference group was $23.1 \%$. Figure 1 shows the TGCS distribution in the study population and the proportion of CS in each group.

The first Robson group was the most frequent (28.0\% of deliveries), while group VIII was the less frequent (1.1\%). The first four groups constitute approximately the $80 \%$ of the entire population. Group V had the highest CS rate (93.6\%), while group III showed the lowest recourse to CS, with a rate of $6.3 \%$. Table 1 reports the number of caesarean deliveries, crude and adjusted caesarean section RRs, their statistical significance, and the percentage variation by hospital. The $R R$ percentage 
Table 6 Crude and adjusted c-section RRs of hospitals in groups V-X

\begin{tabular}{|c|c|c|c|c|c|c|c|c|c|}
\hline Hospital & $\mathrm{n}$ & Crude RR & p-value & Adj* $^{*} R$ & $p$-value & $\%$ variationt & Adjt RR & $p$-value & $\%$ variation $\dagger$ \\
\hline A & 529 & 1.11 & $<0.001$ & 1.09 & $<0.001$ & -1.8 & 1.11 & $<0.001$ & 0.0 \\
\hline B & 251 & 1.17 & $<0.001$ & 1.14 & $<0.001$ & -2.6 & 1.13 & $<0.001$ & -3.4 \\
\hline C & 168 & 1.14 & $<0.001$ & 1.12 & $<0.001$ & -1.8 & 1.12 & $<0.001$ & -1.8 \\
\hline D & 45 & 1.10 & 0.202 & 1.07 & 0.271 & -2.7 & 1.02 & 0.729 & -7.3 \\
\hline$E$ & 286 & 1.07 & 0.057 & 1.06 & 0.046 & -0.9 & 1.06 & 0.027 & -0.9 \\
\hline $\mathrm{F}$ & 348 & 1.01 & 0.760 & 1.03 & 0.285 & 2 & 1.00 & 0.984 & -1.0 \\
\hline G & 270 & 1.10 & 0.006 & 1.11 & $<0.001$ & 0.9 & 1.13 & $<0.001$ & 2.7 \\
\hline $\mathrm{H}$ & 102 & 1.18 & $<0.001$ & 1.15 & $<0.001$ & -2.5 & 1.15 & $<0.001$ & -2.5 \\
\hline । & 295 & 1.20 & $<0.001$ & 1.15 & $<0.001$ & -4.2 & 1.09 & $<0.001$ & -9.2 \\
\hline J & 435 & 1.11 & $<0.001$ & 1.13 & $<0.001$ & 1.8 & 1.09 & $<0.001$ & -1.8 \\
\hline K & 308 & 1.02 & 0.650 & 1.05 & 0.145 & 2.9 & 1.05 & 0.074 & 2.9 \\
\hline L & 1,123 & 0.77 & $<0.001$ & 0.90 & $<0.001$ & 16.9 & 0.91 & $<0.001$ & 18.2 \\
\hline M & 113 & 1.13 & 0.004 & 1.19 & $<0.001$ & 5.3 & 1.12 & $<0.001$ & -0.9 \\
\hline N & 89 & 1.06 & 0.277 & 1.05 & 0.311 & -0.9 & 1.00 & 0.954 & -5.7 \\
\hline O & 338 & 0.99 & 0.850 & 1.08 & 0.014 & 9.1 & 1.04 & 0.143 & 5.1 \\
\hline P & 334 & 1.09 & 0.004 & 1.15 & $<0.001$ & 5.5 & 1.15 & $<0.001$ & 5.5 \\
\hline Q & 833 & 1.08 & 0.002 & 1.11 & $<0.001$ & 2.8 & 1.11 & $<0.001$ & 2.8 \\
\hline $\mathrm{R}$ & 927 & 1.12 & $<0.001$ & 1.20 & $<0.001$ & 7.1 & 1.23 & $<0.001$ & 9.8 \\
\hline$S$ & 212 & 1.21 & $<0.001$ & 1.30 & $<0.001$ & 7.4 & 1.28 & $<0.001$ & 5.8 \\
\hline T & 82 & 1.25 & $<0.001$ & 1.16 & $<0.001$ & -7.2 & 1.12 & 0.001 & -10.4 \\
\hline U & 1,151 & 0.97 & 0.234 & 0.99 & 0.626 & 2.1 & 1.00 & 0.810 & 3.1 \\
\hline V & 975 & 1.11 & $<0.001$ & 1.14 & $<0.001$ & 2.7 & 1.09 & $<0.001$ & -1.8 \\
\hline W & 1,237 & 1.02 & 0.447 & 1.05 & 0.015 & 2.9 & 1.03 & 0.157 & 1.0 \\
\hline$x$ & 1,307 & 1.11 & $<0.001$ & 1.19 & $<0.001$ & 7.2 & 1.14 & $<0.001$ & 2.7 \\
\hline Y & 298 & 1.10 & 0.004 & 1.15 & $<0.001$ & 4.5 & 1.13 & $<0.001$ & 2.7 \\
\hline
\end{tabular}

* Adjusted for Robson group.

† The \% variation is computed as (crude RR-adj RR)*100/crude RR.

+ Adjusted for: age, citizenship, severe co-morbid illness of the mother, HIV, diabetes, hypertension, ante-partum haemorrhage/abruption placentae/placenta praevia, eclampsia/pre-eclampsia, foetal-pelvic disproportion/excessive development of the infant, foetal anomalies, polyhydramnios, oligohydramnios, premature rupture of the membranes, abortion threats/assisted fecundation, congenital malformation, intrauterine growth retardation, post-maturity and macrosomia, multiple pregnancy, previous CS, cephalic/breech presentation.

variations by hospital estimated using the M1 model were very similar with those estimated using M2 model. The M1 adjusted RRs led to percentage variations greater than $10 \%$ in 16 out of 25 hospitals, while the M2 adjusted RRs led to percentage variations greater than $10 \%$ in 15 out of 25 hospitals.

Tables 2, 3, 4, 5 provide the number of caesarean deliveries, crude and adjusted caesarean section RRs, their statistical significance, and the percentage variation by hospital in groups I, II, III, IV. In group I (Table 2), 10 hospitals had a percentage variation greater than $10 \%$, with a very high reduction in adjusted compared to the crude RR for hospital $M(36.9 \%)$. In group II no percentage variation $\geq 10 \%$ was observed. In group III (Table 4), 12 hospitals had a percentage variation in relative risk higher than $10 \%$, and again hospital $M$ proved to have the largest value (36.6\%). In group IV 7 hospitals exhibited variations $\geq 10 \%$ (Table 5).
Lastly, Table 6 reports the number of caesarean deliveries, crude and adjusted caesarean section RRs, their statistical significance, and the percentage variation by hospital for Robson groups V-X. We found that only 2 hospitals (L, T) had a percentage variation greater than $10 \%$.

\section{Discussion}

The aim of the present study was to define a riskadjustment model for inter-hospital comparison, using TGCS classification and variables not included in the TGCS classification that are indications for CS. Our results indicate that TGCS classification should be used to control for the hospital case mix in terms of parity, presentation, gestational age and multiple pregnancy. However, some residual variability, in the overall population and in the I and III groups, is accounted for by clinical and sociodemographic confounders. 
Several studies used different risk adjustment [26-28] techniques to compare CS rates across hospitals. The stratified analyses proposed by Robson with "a priori" criteria of classification seem to overcome the problem of risk adjustment. However, our results suggest that the TGCS classification is not sufficient to remove case mix differences present in the first four TGCS groups, especially groups I and III. Brennan et al. [29], recently demonstrated a wide variation of caesarean section rates in women in spontaneous cephalic term labour (I and III TGCS groups) among 9 international "third level" hospitals and suggested the need to verify the role of other potential confounding factors when comparative evaluation is carried out. Our results incorporate in the analyses some clinical and socio-demographic CS risk factors related to mother and foetus, not included in the TGCS, but do not consider the organizational and process variables such as midwifery care, use of oxytocin to correct dystocia, intrapartum foetal blood sampling mentioned by Brennan et al. [29].

One of the strength of the present study is the opportunity to use two current administrative databases with a very good record linkage (higher then 95\%) and to take advantage of data collected from two different sources. In this study, caesarean section occurrences were evaluated using discharge record data. Accuracy, completeness, and quality of records may differ from hospital to hospital, however the CS rates and proportion of all patients in Robson's groups (data not shown) are similar to those reported in other studies [30,31]. The potential for inconsistencies in coding discharge records may challenge the accuracy of the assessment of outcome and of risk factors. Missing information on important risk factors and errors in coding may in fact lead to subsequent errors in adjustment and this represent a limit of the study. Finally, part of the limitations of administrative data may be due to the basic tension which exists between using the same data for reimbursement and for measuring quality. "When the use is reimbursement, there is a tendency to perform coding quickly and to maximize the coding of complications and comorbidities. When the use is to assess quality, however, it is important for coders to have a complete record and to restrict diagnosis coding to conditions that affect patient care [32]." For instance, hypertension and diabetes may intervene in the algorithm used to determine the case mix of an admission and thus be rewarding in financial terms, whereas this may not be the case for labour induction and history of a previous caesarean. Nevertheless, administrative databases are widely available at the national and regional level, and are currently utilized to compare outcomes, including CS, of inpatient care in Italy [33]. Risk adjustment models should be time and population specific, and have recently proved to be useful for monitoring caesarean section rates and for interhospital comparison [26]. Methods used to develop models based on administrative information can potentially be generalized to other populations.

The TGCS is a good tool for clinical audit practices as it enables professionals to compare their CS practice with homogeneous a priori risk populations. Since low-risk deliveries both in nulliparous and multiparous women are an important target for reduction because in these categories the large majority of inappropriate CS can be found, our analytical method may be useful to partial out the effect of clinical and demographic variables in the TGCS groups. Furthermore, it is important to focus on the first four TGCS groups that in our country represent, given the low fertility rate (1.28 for years 2000-2005) [33] and current obstetric practice in relation to the management of deliveries, about two thirds of all deliveries [34] because in these groups it is most likely to find inappropriate CS.

Reducing the number of unnecessary CS in low-risk women is also a good strategy to indirectly reduce the CS in women with previous CS.

In conclusion, our results indicate that parity and type of labour should be taken into account in risk adjustment models for interhospital comparison. Moreover, Robson's classification proved to be useful to compare caesarean rates among hospitals even though the presence of residual confounding related to clinical and socio-demographic variables within strata may lead to potential bias, especially in low-risk nulliparous and multiparous women with spontaneous labour (groups I and III). Only after eliminating confounders in comparative evaluation of hospital performance we may be confident that we are considering unnecessary variability and inappropriate procedures. Unnecessary variability must be the target for health care quality improvement activities.

\section{Additional file}

Additional file 1: Appendix A. A) ICD 9-CM codes to identify clinical variables from mothers' discharge records. B) ICD 9-CM codes to identify variables from neonatal discharge records. C) ) ICD 9-CM codes to identify variables from both neonatal and maternal discharge records.

\section{Competing interest}

The authors declare that they have no competing interests.

\section{Authors' contributions}

CP: study conception and design, data analysis, interpretation of data. FMP: study conception and design, interpretation of data. FD: study design, data analysis, interpretation of data. CE: data analysis. SE: data analysis. LJ: statistical analysis. PG: interpretation of data. PCA: study conception and design, interpretation of data. All authors read and approved the final manuscript.

\section{Author details}

${ }^{1}$ Department of Epidemiology, Regional Health Service, Lazio Region, Italy. ${ }^{2}$ Department of Medicine and Public Health, University of Bologna, Bologna, Italy. ${ }^{3}$ National Agency of Regional Health Services, Italy. 
Received: 1 April 2011 Accepted: 23 May 2012

Published: 21 June 2012

\section{References}

1. Canadian Institute for Health Information: Giving Birth in Canada: Providers of Maternity and Infart Care. Ottawa. Canada: $\mathrm{ClHI} ; 2004$.

2. MacDorman M, Menacker F, Declercq E: Cesarean birth in the United States: epidemiology, trends, and outcomes. Clin Perinatol 2008, 35:293-307.

3. Belizan J, Althabe F, Cafferata ML: Health consequences of the increasing caesarean section rates. Epidemiology 2007, 18:485-486.

4. Betran AP, Merialdi M, Lauer A, et al: Rates of caesarean section: analysis of global, regional and national estimates. Paediatr Perinat Epidemiol 2007, 21:98-113.

5. Belizan JM, Althabe F, Barros S, et al: Rates and implications of caesarean section in Latin America: ecological study. BMJ 1999, 519:1397-1402.

6. World Health Organization: Appropriate technology for birth. Lancet 1985, 2:436-437.

7. Osservatorio Nazionale sulla Salute nelle Regioni Italiane: Rapporto Osservasalute 2008. In Stato di salute e qualità dell'assistenza nelle regioni italiane.: Milano: Press; 2008.

8. Royal College of Obstetricians and Gynaecologists: Birth after previous caesarean birth. London (UK): RCOG Press; 2007. Green-top guideline; $n^{\circ} 45$.

9. Robson MS: Can we reduce the caesarean section rate? Best Pract Res Clin Obstet Gynaecol 2001, 15:179-194.

10. Meikle SF, Steiner CA, Zhang J, Lawrence WL: A national estimate of the elective primary caesarean delivery rate. Obstet Gynecol 2005, 105(4):751-756.

11. Main EK, Bloomfield L, Hunt G: Sutter Health, First Pregnancy and delivery Clinical Initiative Committee: Development of large-scale obstetric quality-improvement program that focused on the nulliparous patient at term. Am J Obstet Gynecol 2004, 190:1747-56.

12. Kontopoulos EV, Ananth CV, Smulian JC, Vintzileos AM: The impact of route of delivery and presentation on twin neonatal and infant mortality: a population-based study in the USA, 1995-97. J Matern Fetal Neonatal Med 2004, 15(4):219-24.

13. Tamburrano MT, laccarino C, Castagnaro C: Un primo tentativo di analisi dei parti cesarei attraverso le classi di Robson: limiti e potenzialità dei CeDAP. Rapporto Osservasalute 2007, 1:244-250.

14. Regione Emilia-Romagna: La nascita in Emilia-Romagna. $5^{\circ}$ Rapporto sui dati del Certificato di Assistenza al Parto (CedAP) - Anno 2007. Bologna: Regione Emilia-Romagna; 2008:77-107.

15. Fischer A, LaCoursiere DY, Barnard P, et al: Differences Between Hospitals in Cesarean Rates for Term Primigravidas With Cephalic Presentation. Obstet Gynecol 2005, 105(4):816-821.

16. Robson M: Classification of cesarean sections. Fetal Matern Med Rev 2001, 12:23-9.

17. Betrán AP, Gulmezoglu AM, Robson M, et al: WHO global survey on maternal and perinatal health in Latin America: classifying caesarean sections. Reprod Health 2009, 6:18.

18. Torloni MR, Betran AP, Souza JP, et al: Classification for Cesarean Section: A Systemac Review. PLoS One 2011, 6(1):e14566. doi:10.1371/journal. pone.0014566.

19. Gregory KD, Korst LM, Lawrence DP: Variation in elective primary caesarean delivery by patient and hospital factors. Am J Obstet Gynecol 2001, 184:1521-1531.

20. Royal College of Obstetricians and Gynaecologists: National Collaborating Centre for Women's and Children's Health Commissioned by the National Institute for Clinical Excellence. Cesarean Section, clinical guideline. London: RCOG Press; 2004.

21. Shearer El: Caesarean section: medical benefits and costs. Soc Sci Med 1993, 37(10):1223-31. Review.

22. Stivanello E, Rucci P, Carretta E, et al: Risk Adjustment for Inter-Hospital Comparison of Caesarean Delivery Rates in Low-risk Deliveries. PLoS One 2011, 6(11):e28060. doi:10.1371/journal.pone. 0028060.

23. Lazio Regional Health Service (RHS): Outcome Evaluation Program 20062008. ; 2011. Available at: http://151.1.149.72/vislazio_en/metodi_statistici. php. Accessed March 16, 2011.

24. Rothman KJ: Epidemiology. An Introduction. Cary, NC: Oxford University Press; 2002

25. Grayson DA: Confounding confounding. Am J Epidemiol 1987, 126:546-53.
26. lezzoni LI: Risk adjustment for measuring healthcare outcomes. 2nd edition. Chicago, IL: Health Administration Press; 1997.

27. Arcà M, Fusco D, Barone AP, Perucci CA: Risk adjustment and outcome research. Part I. J Cardiovasc Med 2006, 7(9):682-90.

28. Fantini MP, Stivanello E, Frammartino B, et al: Risk adjustment for interhospital comparison of primary cesarean section rates: need, validity and parsimony. BMC Health Serv Res 2006, 6:100.

29. Brennan DJ, Robson MS, Murphy M, et al: Comparative analysis of international cesarean delivery rates using 10-group classification identifies significant variation in spontaneous labor. Am J Obstet Gynecol 2009, 201(3):308.e1-8.

30. McCarthy FP, Rigg L, Cady L, Cullinane F: A new way of looking at caesarean section births. Aust N Z J Obstet Gynaecol 2007, 47:316-320.

31. Scarella A, Chamy V, Sepúlveda M, et al: Medical audit using the Ten Group Classification System and its impact on the cesarean section rate. Eur J Obstet Gynecol Reprod Biol 2011, 154(2):136-40.

32. AHRQ: AHRQuality Indicators e-Newsletter: AHRQ-QI-TIPS: ICD-9-CM Coding Issues; 2005. [http://www.qualityindica tors.ahrq.gov/newsletter/2005September-AHRQ-QI-Newslet ter.htm.

33. Lazio Regional Health Service (RHS): Outcome Evaluation Program 20062008; 2011. Available at: http://151.1.149.72/vislazio/vis_index.php. Accessed March 16, 2011.

34. United Nations Department of Economic and Social Affairs, Population Division: "United Nations World Population Prospects: 2006 revision, Table A.15". New York: UN; 2007. Retrieved 7 December 2009.

doi:10.1186/1471-2393-12-54

Cite this article as: Colais et al:: Risk adjustment models for interhospital comparison of CS rates using Robson's ten group classification system and other socio-demographic and clinical variables. BMC Pregnancy and Childbirth 2012 12:54.

\section{Submit your next manuscript to BioMed Central and take full advantage of:}

- Convenient online submission

- Thorough peer review

- No space constraints or color figure charges

- Immediate publication on acceptance

- Inclusion in PubMed, CAS, Scopus and Google Scholar

- Research which is freely available for redistribution 